\title{
Polymerized human hemoglobin increases the effectiveness of cisplatin-based chemotherapy in non-small cell lung cancer
}

\author{
Alfredo Lucas ${ }^{1}$, Donald A. Belcher ${ }^{2}$, Carlos Munoz ${ }^{1}$, Alexander T. Williams ${ }^{1}$, Andre \\ F. Palmer ${ }^{2}$ and Pedro Cabrales ${ }^{1}$ \\ ${ }^{1}$ Department of Bioengineering, University of California San Diego, La Jolla, CA 92093, USA \\ ${ }^{2}$ William G. Lowrie Department of Chemical and Biomolecular Engineering, The Ohio State University, Columbus, OH 43210, USA \\ Correspondence to: Pedro Cabrales, email: pcabrales@ucsd.edu \\ Keywords: chemotherapy; cisplatin; polymerized hemoglobin; non-small cell lung cancer; hypoxia \\ Received: February 26, $2020 \quad$ Accepted: June 15, $2020 \quad$ Published: October 20, 2020
}

Copyright: 2020 Lucas et al. This is an open access article distributed under the terms of the Creative Commons Attribution License (CC BY 3.0), which permits unrestricted use, distribution, and reproduction in any medium, provided the original author and source are credited.

\section{ABSTRACT}

Cisplatin is a promising therapeutic for the treatment of non-small cell lung cancer (NSCLC). Unfortunately, a significant portion of NSCLC patients relapse due to cisplatin chemoresistance. This chemoresistance is thought to be primarily associated with hypoxia in the tumor microenvironment. Administration of hemoglobin ( $\mathrm{Hb})-$ based oxygen $\left(\mathrm{O}_{2}\right)$ carriers ( $\mathrm{HBOCs}$ ) is a promising strategy to alleviate hypoxia in the tumor, which may make cisplatin more effective. In this study, we administered a high $\mathrm{O}_{2}$ affinity, relaxed state (R-state) polymerized hemoglobin (PolyHb) to three different NSCLC cell lines cultured in vitro and implanted in vivo into healthy mice. The R-state PolyHb administered in this study is unable to deliver $\mathrm{O}_{2}$ unless under severe hypoxia which significantly limits its oxygenation potential. In vitro sensitivity studies indicate that the administration of PolyHb increases the effectiveness of cisplatin under hypoxic conditions. Additional animal studies revealed that coadministration of PolyHb with cisplatin attenuated tumor growth without alleviating hypoxia. Analysis of reactive $\mathrm{O}_{2}$ species production in the presence of hypoxic culture indicates that exogenous ROS production by oxidized PolyHb may the mechanism of chemosensitization. This ROS mechanism, coupled with oxygenation, may be a potential chemosensitizing strategy for use in NSCLC treatment.

\section{INTRODUCTION}

Non-small cell lung cancer (NSCLC) remains one of the leading causes of cancer death and constitutes $\sim 80$ to $85 \%$ of all types of lung cancers [1]. Approximately $40 \%$ of all newly diagnosed NSCLCs are in stage IV, for which cytotoxic combination chemotherapy is the first line of defense [2]. In many combination chemotherapy regimens for NSCLC, cisplatin is used in combination with etoposide [3]. Through large multicenter clinical trials, cisplatin-based combination therapy results in a moderate survival advantage for treating metastatic NSCLC $[4,5]$. However, a significant fraction of patient relapses occur due to cisplatin chemoresistance. Therefore, it is necessary to find novel therapeutic approaches to improve the effects of cisplatin in treating NSCLC.

Cisplatin chemoresistance is associated with the development of hypoxia in the tumor microenvironment.
Hypoxia-induced cisplatin resistance is studied extensively in NSCLC, and multiple mechanisms for its development have been suggested [6-9]. Many mechanisms suggested in the literature involve the expression of hypoxiainducible factor $1 \alpha(\mathrm{HIF}-1 \alpha)$. The expression of HIF- $1 \alpha$, in the presence of moderate hypoxia, activates a series of intracellular regulatory pathways that promote cell survival. Upon activation of HIF-1 $\alpha$, cells predominantly shift towards glycolytic synthesis of ATP, which is promoted by the overexpression of GLUT transporters. HIF-1 $\alpha$ also promotes the increased synthesis of vascular endothelial growth factors (VEGF). These factors promote angiogenesis within the tumor microenvironment, which leads to increased tumor perfusion [10]. Endogenous reactive oxygen species (ROS) are also associated with the expression and stabilization of HIF-1 $\alpha[11,12]$.

Furthermore, the expression of HIF-1 $\alpha$ is associated with the reduction of ROS in cancer cells, which promotes 
cancer cell survival [13]. Cisplatin's mechanism of action involves DNA cross-linking and damage, which results in the initiation of cellular apoptotic pathways [14]. Other studies suggest that cisplatin's cytotoxicity involves the formation of mitochondrial ROS, which can lead to the initiation of apoptotic pathways through mitochondrial membrane damage, as well as more widespread cellular damage [15-19]. Therefore, activation of protective mechanisms via expression of HIF-1 $\alpha$ is likely to affect the efficacy of cisplatin in the presence of hypoxia.

In an attempt to reverse (i.e., oxygenate) the tumor's hypoxic microenvironment, several studies have supplemented cisplatin treatment with hemoglobin-based oxygen carriers (HBOCs) [20-25]. HBOCs often involve chemically cross-linked acellular hemoglobin $(\mathrm{Hb})$ and are capable of transporting oxygen $\left(\mathrm{O}_{2}\right)$. Alterations in the biophysical properties of HBOCs designed to reduce hypoxia may lead to targeted $\mathrm{O}_{2}$ release in the tumor [26]. This targeted $\mathrm{O}_{2}$ release may alleviate hypoxia-induced cisplatin resistance. However, this is difficult to achieve in practice. The above studies have been capable of effectively increasing the sensitivity of cancerous cells to cisplatin, both in vitro and in vivo, via supplementation of HBOCs, and they attribute this gained efficacy to increased $\mathrm{O}_{2}$ delivery. However, the concentrations of $\mathrm{HBOC}$ used in previous studies were insufficient to provide a significant increase in tumor $\mathrm{O}_{2}$ delivery. This indicates that HBOC mediated tumor oxygenation is not the sole reason for the increased sensitivity to chemotherapy.

An alternative explanation for increased chemosensitivity in the presence of HBOCs is the accumulation of ROS in the tumor microenvironment as a result of $\mathrm{Hb}$ oxidation reactions. This latter hypothesis has not been directly evaluated in the existing cancer literature. Hence, this study explores both mechanisms, i. e., the increase in oxygenation of the tumor and the catalyzed formation of ROS by the HBOC, in in vitro and in vivo studies using low molecular weight (MW) polymerized human $\mathrm{Hb}$ (PolyHb) in the relaxed (R) quaternary state. R-state PolyHb has an extremely high $\mathrm{O}_{2}$ affinity $\left(\mathrm{P}_{50} \sim 1.5 \mathrm{~mm} \mathrm{Hg}\right)$, which limits $\mathrm{O}_{2}$ release to only regions suffering from severe hypoxia. Thus, the mechanism of action of R-state PolyHb may be due to its role in ROS generation.

In this study, PolyHb was administered in conjunction with cisplatin to three different NSCLC cell lines cultured in vitro and implanted in vivo into healthy mice. HIF- $1 \alpha$ and ROS expression in the presence and absence of PolyHb, without cisplatin, was assessed in hypoxic cell culture. The in vitro sensitivity to cisplatin, in the absence and presence of PolyHb at different concentrations, was also assessed through markers of apoptosis and necrosis, as well as through sensitivity analysis. Differences in the in vivo tumor volume were assessed longitudinally in the presence of cisplatin treatment with and without PolyHb supplementation.

\section{RESULTS}

\section{PolyHb properties}

Polymerization of human $\mathrm{hHb}$ in the relaxed (R) quaternary state resulted in significant changes in its biophysical properties (Figure 1). Polymerization in the R-state significantly increased the $\mathrm{O}_{2}$ affinity $\left(\mathrm{P}_{50}=1.8 \pm\right.$ $0.1 \mathrm{~mm} \mathrm{Hg})$ compared to $\mathrm{hHb}(12.1 \pm 0.5 \mathrm{~mm} \mathrm{Hg})$. The $\mathrm{O}_{2}$ affinity of 25:1 R-state PolyHb was also much greater than mouse RBCs $(42.1 \pm 0.9 \mathrm{~mm} \mathrm{Hg})$. After polymerization, 25:1 R-state PolyHb no longer had a sigmoidal $\mathrm{O}_{2}$ binding curve, which indicates a loss of cooperative binding behavior. The effective hydrodynamic diameter of 25:1 R-state PolyHb was significantly larger $\left(\mathrm{D}_{\text {eff }}=26.7 \pm 3.2\right.$ $\mathrm{nm}$ ) compared to unmodified $\mathrm{hHb}$, as measured by $\mathrm{Xu}$ et al. (5 nm) [27]. Analysis of the chromatogram obtained with SEC-HPLC revealed the complete removal of extremely low MW PolyHb and unpolymerized $\mathrm{Hb}$ (128 $\mathrm{kDa}, 64 \mathrm{kDa}$ ) in the transfused sample. R-state PolyHb had significantly slower rates of auto-oxidation $\left(\mathrm{k}_{\text {fast }}=\right.$ $\left.0.0127 \pm 0.0008 \mathrm{~h}^{-1}, \mathrm{k}_{\text {slow }}=0.0067 \pm 0.0003 \mathrm{~h}^{-1}\right)$ compared to unmodified $\mathrm{Hb}\left(0.0166 \pm 0.0009 \mathrm{~h}^{-1}\right)$.

\section{ROS quantification}

Incubation of A549 cells with PolyHb for 24 hours resulted in a significantly increased expression of ROS relative to the control group (Figure $2 \mathrm{~A}-2 \mathrm{~B}$ ). Incubation with PolyHb also reduced the expression of the hypoxia marker HIF-1 $\alpha$ and the p53 oncogene (Figure 2C).

\section{Tumor cell viability in culture}

The tumor cell viability in culture, as measured by the percentage of live cells after treatment with the three treatment groups, for the H24, H460, and A549 cell lines are shown in Figure 3. For H23 cells, the concentrations at which half of the cells became unviable (IC50) for cisplatin, cisplatin with PolyHb at $0.1 \mathrm{~g} / \mathrm{dL}$, and cisplatin with PolyHb at $0.2 \mathrm{~g} / \mathrm{dL}$ were $2.85 \mu \mathrm{M}, 1.69 \mu \mathrm{M}$, and 0.80 $\mu \mathrm{M}$, respectively. For H460 cells, the IC50 for cisplatin, cisplatin with PolyHb at $0.1 \mathrm{~g} / \mathrm{dL}$ and cisplatin with PolyHb at $0.2 \mathrm{~g} / \mathrm{dL}$ were $1.31 \mu \mathrm{M}, 0.66 \mu \mathrm{M}$, and 0.37 $\mu \mathrm{M}$, respectively. Finally, for H549 cells, the IC50 for cisplatin, cisplatin with PolyHb at $0.1 \mathrm{~g} / \mathrm{dL}$, and cisplatin with PolyHb at $0.2 \mathrm{~g} / \mathrm{dL}$ were $5.27 \mu \mathrm{M}, 2.47 \mu \mathrm{M}$, and 1.31 $\mu \mathrm{M}$, respectively. These results indicate that the largest decrease in cell viability during hypoxia, for the three studied cell types, was produced from treatment with cisplatin and PolyHb at a $0.2 \mathrm{~g} / \mathrm{dL}$ concentration.

\section{Apoptosis and necrosis}

The percentage of viable cells (negative for annexin $\mathrm{V}$ and PI), early apoptotic (positive for annexin $\mathrm{V}$ and 
negative for PI), late apoptotic (positive for annexin $\mathrm{V}$ and PI), and necrotic (positive for PI and negative for annexin $\mathrm{V})$ cells after $48 \mathrm{~h}$ of treatment is presented in Figure 3. For H23 cells, treatment with both concentrations of PolyHb did not significantly increase the number of necrotic cells relative to the cisplatin-only treatment group. The presence of $0.2 \mathrm{~g} / \mathrm{dL}$ PolyHb significantly increased the number of cells undergoing apoptosis relative to 0.1 $\mathrm{g} / \mathrm{dL}$ PolyHb and control treatment groups. Relative to cisplatin-only treatment, the number of co-stained cells (undergoing apoptosis and were already necrotic) significantly increased in the presence of PolyHb. Furthermore, positive co-staining was proportional to the concentration of PolyHb. The $0.1 \mathrm{~g} / \mathrm{dL}$ PolyHb group had significantly lower positive co-staining than the 0.2 $\mathrm{g} / \mathrm{dL}$ group. Overall, the total number of viable cells, as determined by the negatively stained cells, was the same for both cisplatin alone and cisplatin with $0.1 \mathrm{~g} /$ $\mathrm{dL}$ PolyHb. The number of viable cells was significantly lower for cisplatin with $0.2 \mathrm{~g} / \mathrm{dL}$ PolyHb.

For H460 cells, the presence of PolyHb, at both concentrations, significantly increased the number of both apoptotic and necrotic cells. While PolyHb concentration does not have an effect on the number of apoptotic cells or necrotic cells separately, the number of co-stained cells in the presence of $0.2 \mathrm{~g} / \mathrm{dL}$ PolyHb was significantly higher than the number of co-stained cells in the presence of $0.1 \mathrm{~g} / \mathrm{dL}$ PolyHb. Cisplatin combined with PolyHb had a significantly higher number of co-stained cells compared to cells treated with cisplatin alone. The number of viable cells followed an inverse trend to the positively co-stained cells. The most significant quantity of viable cells was present in the cisplatin-only group. A significantly lower number of viable cells were found when cisplatin was combined with $0.1 \mathrm{~g} / \mathrm{dL}$ PolyHb. Finally, the least number of viable cells was found in the cisplatin combined with $0.2 \mathrm{~g} / \mathrm{dL}$ PolyHb.

For A549 cells, a similar behavior to the H23 cells was observed. In the A549 cell line, the presence of PolyHb does not change the number of cells positively stained for necrosis, relative to cisplatin-only treatment. However, the presence of PolyHb significantly increased the number of cells undergoing apoptosis, relative to the cisplatin-only treatment. This increase was independent of PolyHb concentration. While there was a significant increase in the number of positively co-stained cells in the
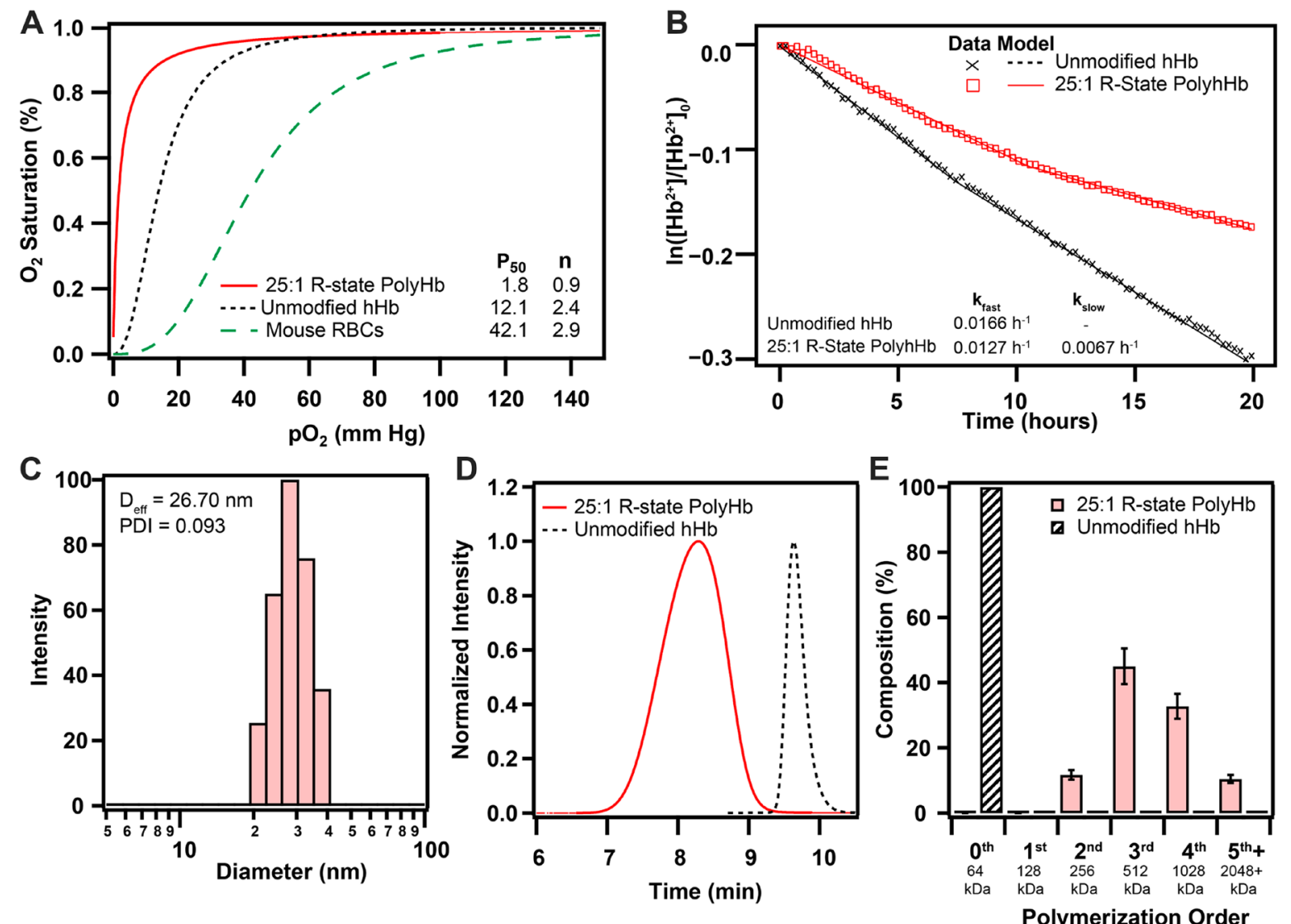

Figure 1: Biophysical properties of 25:1 R-state PolyHb used for this study. (A) $\mathrm{O}_{2}$ equilibrium curves for 25:1 R-state PolyHb, $\mathrm{hHb}$, and mouse RBCs. (B) Auto-oxidation kinetics of $\mathrm{hHb}$ and 25:1 R-state PolyHb (1.25 g/dL). (C) Intensity distributions of hydrodynamic diameter of 25:1 R-State PolyHb. (D) Normalized SEC-HPLC intensity distributions of R-state PolyHb compared to unmodified hHb. (E) Polymer order distribution for 25:1 R-State PolyHbs. Polymer distribution was calculated on a percent by heme basis via analysis of the 413 $\mathrm{nm}$ absorbance wavelength. The corresponding approximate sizes of the polymer orders are shown below each group. 
presence of PolyHb, there were no statistical differences between the two PolyHb concentrations. As with the other cell types, the highest number of viable cells was found in the cisplatin-only treatment group. A smaller number of viable cells was observed when cisplatin was combined with $0.1 \mathrm{~g} / \mathrm{dL}$ PolyHb. The least number of viable cells was observed in the cisplatin combined with $0.1 \mathrm{~g} / \mathrm{dL}$ PolyHb. All differences for the viable cells were statistically significant.

\section{In vivo tumor size}

The changes in tumor size for mice implanted with H23, H460, and A549 cells followed by treatment with cisplatin-only, cisplatin-PolyHb combination, and vehicle control are shown in Figure 4. Regardless of treatment, each tumor cell line had different growth rates. H460 had the highest rate of growth, followed by A549 and then $\mathrm{H} 23$.

Starting at day 15 of treatment, H23 tumor volumes were significantly smaller when treated with cisplatin combined with PolyHb, compared to the vehicle control. This statistically significant smaller volume was preserved at days 22 and 29 of treatment. At these time points, the cisplatin-PolyHb combined treatment had significantly smaller tumor volumes compared to tumor volumes when treated with cisplatin alone. At days 22 and 29 of treatment, the cisplatin-only treatment group had statistically smaller tumor volumes compared to the vehicle group.

At days 8 and 10, H460 tumors treated with cisplatin-only and the cisplatin-PolyHb combined treatment group were significantly smaller compared to treatment with the vehicle control. At days 12 and 14 of treatment, the cisplatin with PolyHb treatment group had a significantly smaller tumor volume than the other two treatment groups, and the cisplatin-only group had a tumor volume only significantly smaller than that of the vehicle group.

The different treatments had no significant effect on A549 tumor volume until day 12 of treatment. On day 12, the vehicle and cisplatin-only groups had similar tumor volumes. The cisplatin with PolyHb treatment group had significantly smaller tumor volume compared to the other treatments. On day 16 , the cisplatin with PolyHb group had significantly smaller tumor volume compared to the cisplatin-only and vehicle groups. At this time point, the cisplatin-only group had significantly smaller tumor volume compared to the vehicle group.

\section{In vivo HIF expression}

The expression of HIF-1 $\alpha$ and HIF- $2 \alpha$ measured by Western blot analysis in the A549 tumor is shown in
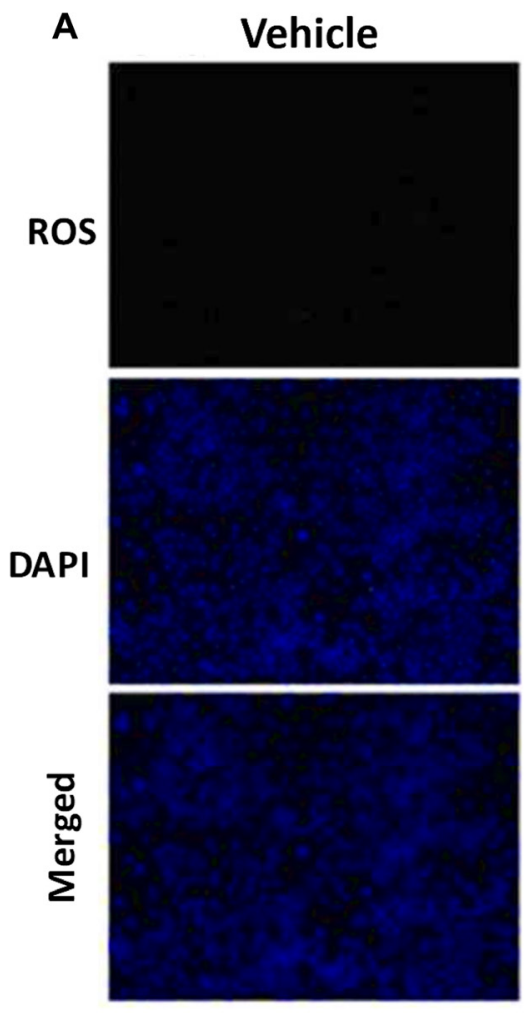

PolyHb
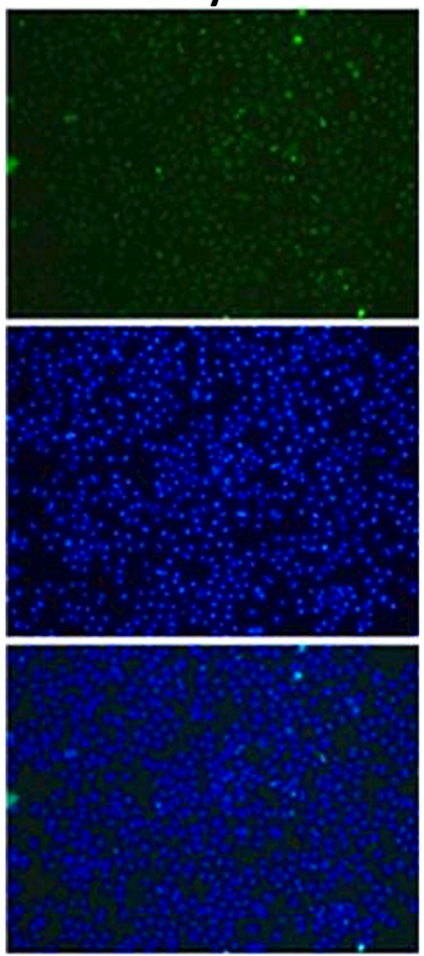

B

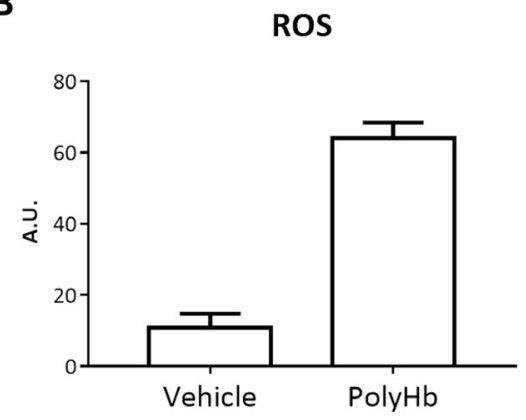

\section{Vehicle PolyHb}

Hif-1 $\alpha$

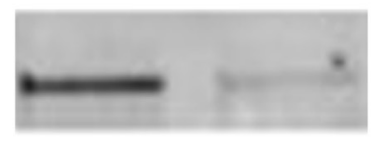

P53

\section{Actin}

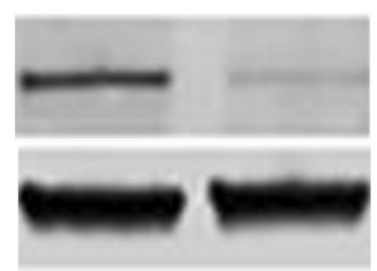

Figure 2: Effects of $\mathbf{0 . 0 5}$ g/dL PolyHb on ROS levels in A549 cells after 24 hours. (A) ROS (DCFH-DA) and DAPI stain are shown for PolyHb and a vehicle control. (B) ROS (DCFH-DA) fluorescent intensity of digested A549 cells after 24 hour exposure to PolyHb and a vehicle control. (C) Effects of PolyHb and a vehicle control on expression of HIF-1 $\alpha$, p53, and actin, as assessed by western blot. 
Figure 5. Figure 5B shows the average intensity of the HIF-1 $\alpha$ and HIF-2 $\alpha$ bands for each experimental group, normalized to the vehicle control. While none of the differences were statistically significant, for both HIF-1 $\alpha$ and HIF- $2 \alpha$, the presence of PolyHb caused a decrease in the amount HIF-1 $\alpha$ and HIF-2 $\alpha$ expression with PolyHb + cisplatin compared to the cisplatin only group.

\section{DISCUSSION}

The principal finding of this study is that a high $\mathrm{O}_{2}$ affinity R-state PolyHb increases the sensitivity of NSCLC to cisplatin by promoting the formation of ROS and suppressing hypoxia-induced cisplatin resistance. These results are consistent with previous studies of HBOC facilitated chemosensitization [20-23]. Many previous studies attribute the sensitization of cisplatin to increased $\mathrm{O}_{2}$ delivery from the HBOC to the tumor [28-30]. While this hypothesis is part of the explanation, it does not fully explain our observations. The increased ROS expression after exposure to PolyHb in the A549 cells grown in vitro occurs despite the decrease in hypoxia markers HIF-1 $\alpha$ and $\mathrm{p} 53$. This increase in ROS expression colocalized with dead cells (positively stained DAPI cells). Although the hypoxia markers were not overexpressed, ROS expression was still high for the PolyHb group. Therefore, the ROS may not be endogenously generated by the cells due to the hypoxic environment. Instead, these ROS may be generated by the PolyHb.

Weekly treatment with low MW PolyHb at low doses insufficient to increase blood $\mathrm{O}_{2}$ carrying capacity with short circulatory half-life (10 hours intravascular half-life) limits the oxygenation potential of PolyHb as a cisplatin sensitizing mechanism in NSCLC. In our previous study, we dosed every two days with higher concentrations of large MW PolyHb (24 hours intravascular half-life) to significantly increase oxygenation in breast tumors and directly induce $\mathrm{O}_{2}$ dependent antitumor activity [26, 31].

Free $\mathrm{Hb}$ can undergo auto-oxidation to methemoglobin (metHb), thereby producing free radicals [32]. $\mathrm{Hb}$ readily undergoes one-electron oxidations and reductions acting as a source and sink of free radicals. The auto-oxidation of heme produces $\mathrm{O}_{2}^{-}$and, indirectly, $\mathrm{H}_{2} \mathrm{O}_{2}$. $\mathrm{Hb}$ can react with redox-active xenobiotics and metabolites, forming xenobiotic and metabolite radicals that initiate a series of ROS generating reactions [33]. The oxidation of oxyhemoglobin produces $\mathrm{O}_{2}^{-}$, metHb $\left(\mathrm{HbFe}^{3+}\right)$, and ferrylhemoglobin $\left(\mathrm{HbFe}^{4+}\right)$. MetHb loses heme at rates substantially higher than ferrylhemoglobin [34] and is converted to hemichrome forming Heinz bodies [33]. MetHb and ferrylhemoglobin reactions with radicals produce ferryl radicals with potent toxic effects [33]. This

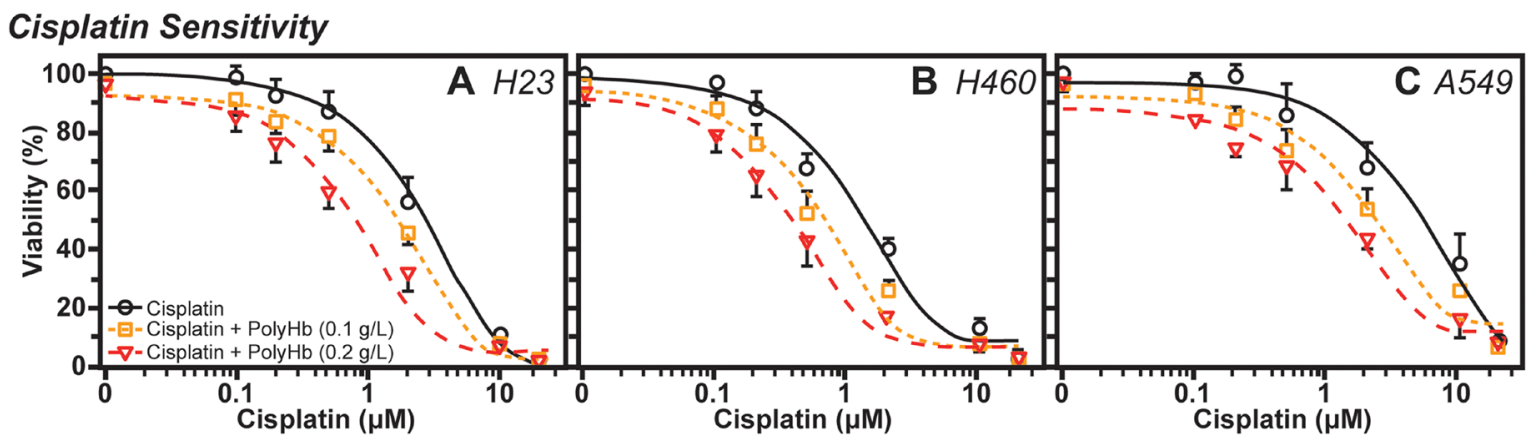

Cisplatin Cytotoxicity (Cisplatin Dose $=0.2 \mu \mathrm{M}$ )

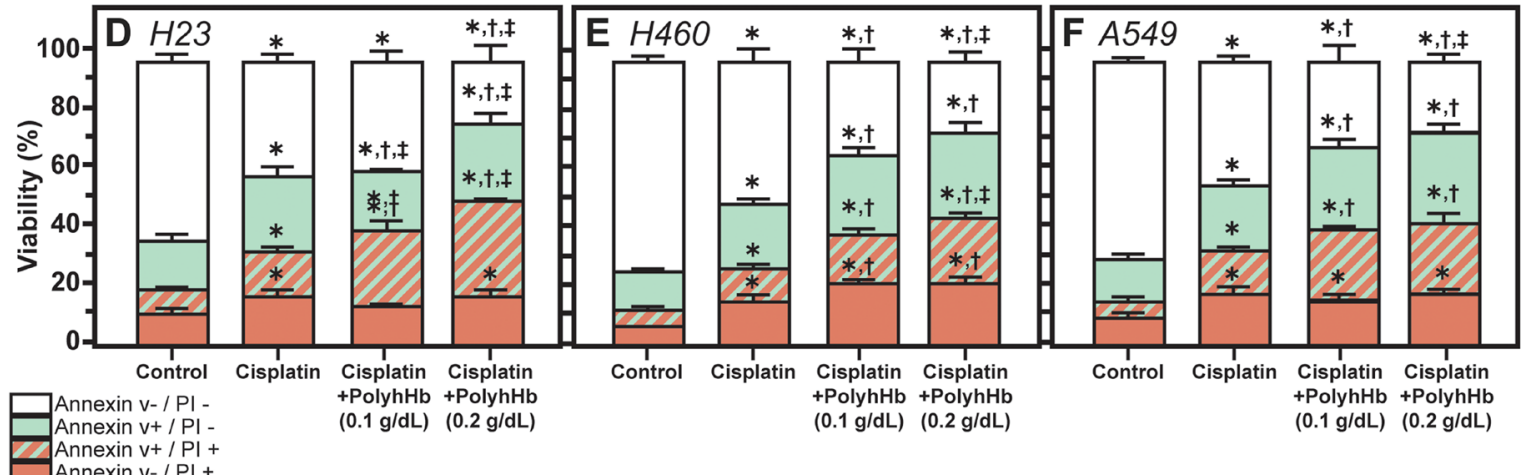

Figure 3: Effects of Cisplatin and PolyHb on cell viability and cytotoxicity. (TOP) Shift in cisplatin sensitivity in (A) H23, (B) H460, and (C) A549 cell lines upon addition of 0.1 or $0.2 \mathrm{~g} / \mathrm{dL}$ of PolyHb. Curves represent the mean percentage of viable cells (mean \pm $\mathrm{SD})$ relative to $0 \mu \mathrm{M}$ cisplatin ( $n=5$ total). (BOTTOM) Cisplatin cytotoxicity in $(\mathbf{D}) \mathrm{H} 23,(\mathbf{E}) \mathrm{H} 460$, and (F) A549 cell lines upon addition of 0.1 or $0.2 \mathrm{~g} / \mathrm{dL}$ of PolyHb (mean $\pm \mathrm{SD}, n=5$ ). The cisplatin dose was $0.2 \mu \mathrm{M}$ in all groups treated for 48 h. *significant with respect to the control group; ${ }^{\dagger}$ significant with respect to the cisplatin-only group; ${ }^{*}$ significant with respect to the cisplatin $+\mathrm{PolyHb}(0.1 \mathrm{~g} / \mathrm{dL}) \mathrm{group}$. 
naturally occurring process inside red blood cells (RBCs) is suppressed by the highly specialized antioxidant system found in RBCs, which rapidly neutralizes ROS. Since many HBOCs are modified or cross-linked versions of acellular/cell-free $\mathrm{Hb}$, the ROS generated from these autooxidation events cannot be readily neutralized through the endogenous RBC machinery [35]. High concentrations of low MW PolyHb, when used at high doses, induce coronary microcirculation toxicity due to oxidative stress [36]. Newer generations of HBOCs are coupled with antioxidants to minimize free radical formation [37]. The dramatic decrease in auto-oxidation of PolyHb and the precursor $\mathrm{Hb}$ solution compared to pure $\mathrm{Hb}$ likely results from copolymerization of superoxide dismutase and catalase that is present in the precursor $\mathrm{Hb}$ solution $[38,39]$.
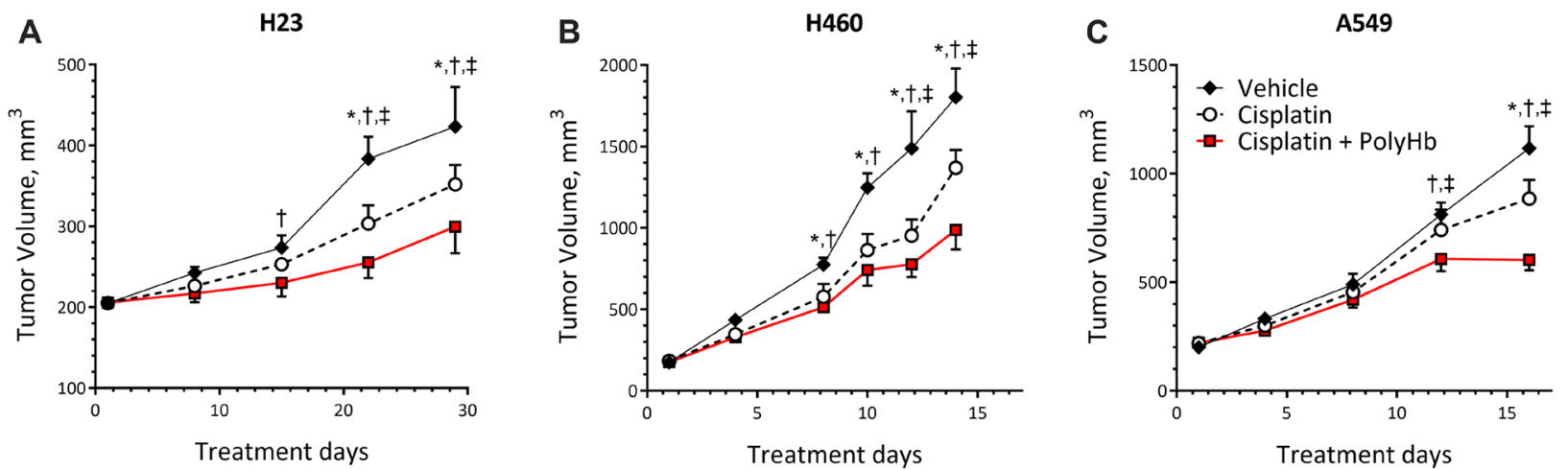

Figure 4: Tumor growth curves of (A) H23, (B) H460, and (C) A549 tumor grafts. Tumors were transplanted subcutaneously in the right flank of female BALB/c nude mice $(n=5)$. Tumor volume was calculated as $(\mathrm{L} \times \mathrm{W}) / 2$. Data represent the mean $\pm \mathrm{SD}$. ${ }^{*} p<0.05$ compared to the control group; ${ }^{\dagger} p<0.05$ compared to the cisplatin-only group; ${ }^{\ddagger} p<0.05$ compared to the cisplatin + PolyHb $(0.1 \mathrm{~g} / \mathrm{dL})$ group.
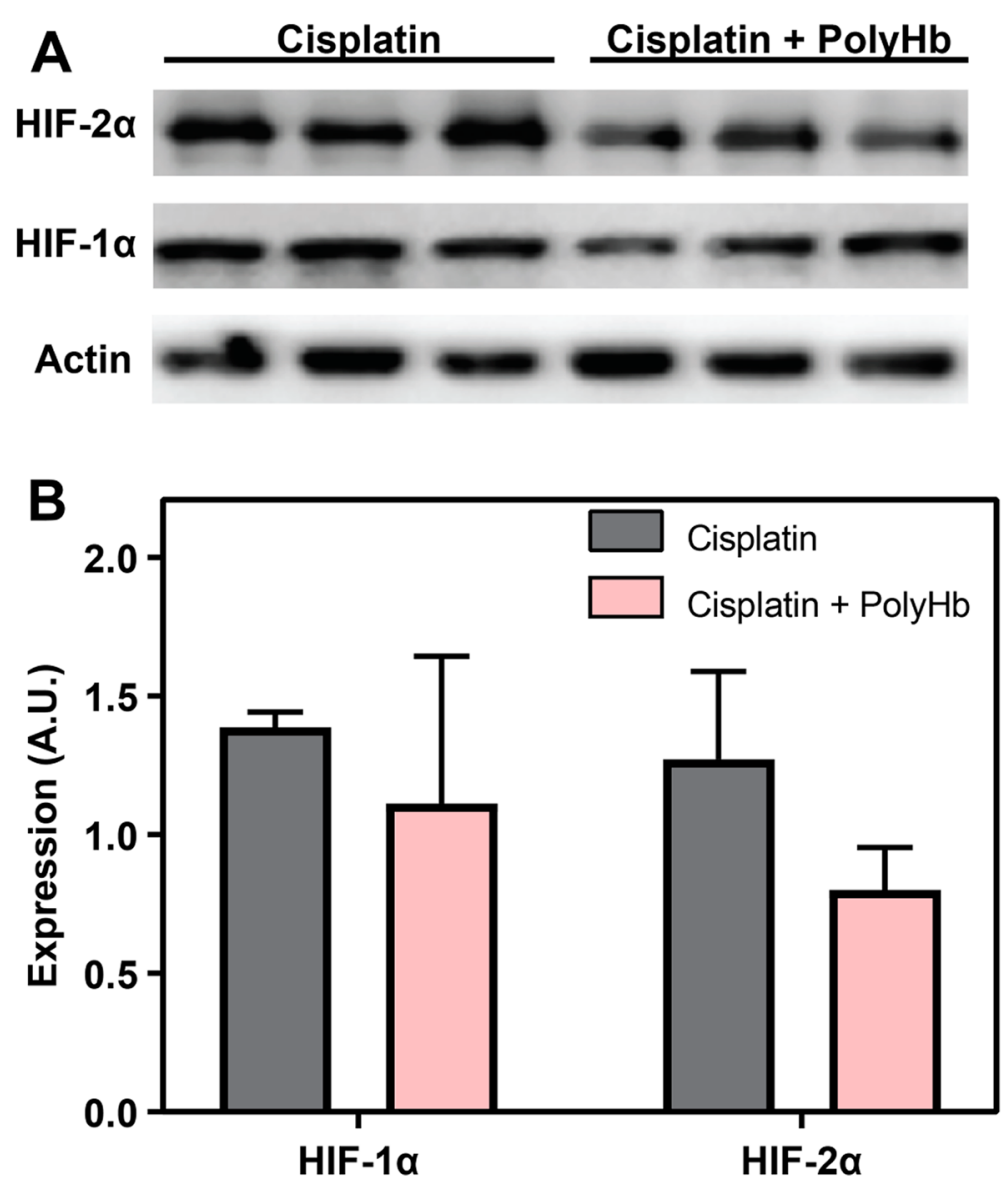

Figure 5: (A) Expression of HIF-1 $\alpha$ and HIF-2 $\alpha$ measured by Western blot analysis in the in-vivo A549 tumor. (B) Average intensity of the HIF- $1 \alpha$ and HIF-2 $\alpha$ bands for each experimental group, normalized to the vehicle control. 
The ROS generating ability combined with hypoxic reduction have a synergistic interaction. HIF-1 $\alpha$ and p53 are fundamental mechanisms of cancer cells that reduce oxidative damage and prevent cell death [6]. Guo et al. showed that the hypoxia-induced cisplatin resistance in A549 cells is regulated by the expression of HIF-1 $\alpha$ and p53, which actively promotes the molecular mechanisms that prevent the accumulation of damaging ROS inside cancer cells [6]. The PolyHb used in this study was in a N-acetyl-L-cysteine (NALC) modified Ringer's Lactate solution. NALC is capable of slowly reducing hydrogen peroxide generated by the PolyHb species, which decreases oxidation of ferrous R-state PolyHb into the $\mathrm{Fe}^{3+}$ state [40]. However, it is insufficient to fully attenuate ROS generation that may damage cells at the cell interface.

Therefore, PolyHb increases the activity of cisplatin by preventing the expression of HIF-1 $\alpha$ and p53 through moderately increasing the level of $\mathrm{O}_{2}$ available to the cell, while exogenously contributing to ROS levels. This hypothesis has been proposed and validated by previous research which demonstrated that increased ROS production reduces the hypoxia-induced cisplatin resistance in vitro [7]. Hb mediated iron and ROS can be considered as potential anti-cancer agents alone or when combined with chemotherapy, as both alter cancer cell mitochondrial oxidative metabolism resulting in increased levels of $\mathrm{O}_{2}^{-}$and $\mathrm{H}_{2} \mathrm{O}_{2}$ [41]. The increased in vitro cisplatin sensitivity in the presence of PolyHb was apparent in the sensitivity curves shown in Figure 3. While an in-depth ROS analysis, such as the one shown in the A549 cells, was not carried out for H23 and H460 cells, the increased in vitro sensitivity to cisplatin in these two additional cancer cell types can be attributed to similar mechanisms. Furthermore, these sensitivity curves also show that the increase in sensitivity is dependent on the concentration of PolyHb. The PolyHb concentration-dependent effect of cisplatin sensitization is likely due to increased ROS formation in the presence of PolyHb. The increase in PolyHb concentration may also increase $\mathrm{O}_{2}$ availability to the cells. However, because HIF-1 $\alpha$ and p53 expression in A549 cells was already decreased after exposure to $0.05 \mathrm{~g} /$ $\mathrm{dL}$ PolyHb, further increases in the PolyHb concentration may not lead to significant hypoxia reduction. This suggests that differences in sensitivity between the two PolyHb concentrations result primarily from the increased formation of ROS at higher PolyHb concentrations.

Apoptotic and necrotic markers are also affected by PolyHb addition to cisplatin-treated cells. The addition of cisplatin alone significantly increased the number of cells that are apoptotic, necrotic, or a combination of the two. This increase in apoptosis is consistent with the known increase in cancer cell apoptosis in the presence of cisplatin [42]. Cisplatin's mechanism of action involves DNA cross-linking and damage, which results in the initiation of cellular apoptotic pathways [14]. Other studies suggest that cisplatin's cytotoxicity involves the formation of mitochondrial ROS, which leads to the initiation of apoptotic pathways through mitochondrial membrane damage and widespread cellular damage [1519]. In hypoxia, upregulation of HIF- $1 \alpha$ and $\mathrm{p} 53$ promotes the reduction of ROS, leading to cisplatin resistance $[6,7]$. Therefore, PolyHb's ability to prevent HIF-1 $\alpha$ and p53 expression in vitro, as shown in the A549 cells, increases the availability of ROS capable of contributing to apoptotic pathways.

Furthermore, PolyHb is capable of contributing exogenous ROS to the cells, which can further promote apoptotic mechanisms. This may be the mechanism for the increased apoptosis observed in the presence of cisplatin and PolyHb, compared to cisplatin alone. For H460 and the A549 cells, there was no significant increase in apoptosis when doubling the PolyHb concentration. However, the number of viable cells was significantly lower when exposed to a higher PolyHb concentration. The decrease in viable cells suggests that moderate increases in apoptosis and necrosis were promoted by the increased PolyHb concentration. Thus, the increase in PolyHb derived ROS is likely the cause of increased cell death relative to increased $\mathrm{O}_{2}$ delivery. Further analysis of the apoptotic and necrotic pathways is required to confirm any solid conclusion.

In vitro and in vivo sensitization of NSCLC cisplatin sensitization via PolyHb were similar. PolyHb and cisplatin synergistically significantly decreased tumor volume. At the end of the measurement period for each tumor type, the tumor volume after transfusing cisplatin-PolyHb together was always significantly less than the volume of the cisplatin-only and vehicle groups. Semiqualitative Western blot analysis of A549 implanted tissue demonstrated that, while not statistically significant, there was a decrease in the expression of HIF-1 and HIF-2 in the presence of PolyHb. This suggests that PolyHb had a minimal effect on reducing the hypoxic environment of the tumor. However, it is unlikely that this was the primary mechanism of cisplatin sensitization in vivo.

Other small MW HBOCs, such as YQ23, leave the intravascular compartment into the tumor microenvironment, which directly increases $\mathrm{O}_{2}$ availability to the tumor [22]. The extravasation of YQ23 has been attributed to its ability to decrease tumor volume [22]. Measurements of tumor $\mathrm{pO}_{2}$ with $\mathrm{YQ}_{23}$ show a significant increase in tumor $\mathrm{O}_{2}$ tension (up to $5 \mathrm{~mm}$ $\mathrm{Hg}$ ) relative to the absence of the carrier at doses of $0.2 \mathrm{~g} / \mathrm{kg}$ and $0.4 \mathrm{~g} / \mathrm{kg}[20,22]$. In these studies, YQ23 intravascular peak concentrations were between $0.3 \mathrm{~g} /$ $\mathrm{dL}$ and $0.8 \mathrm{~g} / \mathrm{dL}$ assuming normal mice body weights $[20,22]$. Although YQ23 is a different configuration of tetrameric $\mathrm{Hb}$, the $\mathrm{O}_{2}$ carrying capacity is the same as tetrameric $\mathrm{Hb}\left(1.36 \mathrm{mLO}_{2} / \mathrm{gHb}\right)$. Given the low solubility of $\mathrm{O}_{2}$ in blood $\left(0.0031 \mathrm{mLO}_{2} / \mathrm{mm} \mathrm{Hg} / \mathrm{dL}\right.$ at $\left.37^{\circ} \mathrm{C}\right)$ in plasma, the maximum resulting increase in $\mathrm{pO}_{2}$ for the 
peak intravascular concentrations of YQ23 should be 2.7 $\mathrm{mm} \mathrm{Hg} / \mathrm{dL}$ and $5.4 \mathrm{~mm} \mathrm{Hg} / \mathrm{dL}$, respectively. For the two studies $0.43 \mathrm{~mm} \mathrm{Hg} / \mathrm{min}$ and $0.22 \mathrm{~mm} \mathrm{Hg} / \mathrm{min}$ of oxygen would be delivered to the tissues respectively, given an approximate cardiac output in mice equivalent to $8 \mathrm{~mL} /$ min. Using an endogenous $\mathrm{Hb}$ concentration of $15 \mathrm{~g} / \mathrm{dL}$, the baseline $\mathrm{O}_{2}$ delivery in mice is about $11 \mathrm{~mm} \mathrm{Hg} / \mathrm{min}$. From this analysis, the increase in $\mathrm{O}_{2}$ delivery provided by YQ23 is minimal, and unlikely to cause the increases in tumor $\mathrm{O}_{2}$ reported $[20,22]$. Meeting the increase in $\mathrm{O}_{2}$ delivery would require that YQ23 to be exclusively releasing $\mathrm{O}_{2}$ to the tumor, for more than 10 minutes, without any $\mathrm{O}_{2}$ consumption by other tissues. If a similar analysis is carried out with the PolyHb used in this study with a dose of $1.6 \mathrm{~g} / \mathrm{kg}(3.75 \times$ dose used in [22]), then the additional $\mathrm{O}_{2}$ delivery supported by PolyHb would be $1.6 \mathrm{~mm} \mathrm{Hg} / \mathrm{min}$. This amount is only $\sim 14 \%$ of the endogenous $\mathrm{O}_{2}$ delivery of the animal. While both YQ23 and PolyHb may have physical properties that might allow for localization of the molecules in the peritumor area it is an oversimplification to assume that HBOCs will exclusively release $\mathrm{O}_{2}$ to the peritumor area if the HBOCs accumulate in that location.

Given that HBOCs accumulate in the peritumor area, $\mathrm{Hb}$ auto-oxidation is likely to cause the most significant increase in ROS in these regions. $\mathrm{Hb}$, under physiological conditions (i.e., inside the $\mathrm{RBC}$ ), autoxidizes at a rate of about 3\% per day [43]. Outside the RBC, with the influence of external factors such as varying $\mathrm{pH}$ and ionic concentrations, this oxidation rate is greatly affected. As presented in [44], the rate of auto-oxidation of human $\mathrm{Hb}$ is faster at more acidic pHs. The auto-oxidation of HBOCs is likely to increase in the tumor microenvironment due to increased acidity resulting from increased anaerobic glycolysis and the presence of proton pumps that promote an acidic environment [45]. Therefore, the accumulation of HBOCs in the tumor microenvironment and a likely increase in $\mathrm{Hb}$ auto-oxidation indicate that increased ROS generation and accumulation can lead to increased damage to the cancer cells in the tumor, thus explaining the decreased tumor volumes in the presence of PolyHb and cisplatin.

This study serves as preliminary evidence of PolyHb's ability to increase the sensitivity to cisplatin in NSCLC. However, these results are limited because the exact mechanism of sensitization is still unclear. The evidence presented in this study suggests that decreased hypoxia due to facilitated $\mathrm{O}_{2}$ delivery combined with endogenous $\mathrm{O}_{2}$ delivery in the animal might have a small effect on cisplatin sensitization. However, a second, but more likely mechanism, auto-oxidation of PolyHb in the tumor microenvironment can lead to the formation of ROS that can enhance the cytotoxicity of cisplatin. Future studies should aim at utilizing in vivo approaches for both ROS detection [46] and intravascular oxygenation [47] in the implanted tumors, as an approach for determining the effects of PolyHb in these two essential processes. Additionally, these studies should consider incorporating superoxide disumatase and catalase to evaluate the exact modes of ROS generation that influence the chemosensitization mechanism as a function of environmental $\mathrm{O}_{2}$ tension. Future studies should also explore how administration of PolyHb solutions modulate proly hydroxylase (PHD), gene expression, and protein expression after extended doses.

\section{MATERIALS AND METHODS}

\section{Polymerized hemoglobin preparation and analysis}

R-state PolyHb was prepared from human $\mathrm{Hb}$ (hHb) extracted from human RBCs as described previously [48]. After purifying the material, we measured the biophysical properties of the PolyHb [31]. The cyanomethemoglobin method was used to measure the $\mathrm{Hb}$ concentration and the methemoglobin (metHb) level of hHb/PolyHb solutions [49, 50]. The size distribution by volume of PolyHb was measured using dynamic light scattering (DLS) (Brookhaven Instrument Inc. BS-200M, Holtsville, NY). The $\mathrm{O}_{2}-\mathrm{hHb} / \mathrm{PolyHb}$ equilibrium binding curves were generated using a Hemox Analyzer (TCS Scientific Corp., New Hope, PA). The rheology of PolyHb plasma mixtures was measured using a DV3T-CP cone and plate rheometer (Brookfield AMETEK, Middleboro, MA) with cone spindle CPA40Z [26]. The MW distribution was estimated with an Acclaim SEC-1000 column (Thermo Scientific, Waltham, MA) connected to a Thermo Scientific Dionex Ultimate HPLC/UHPLC system [38]. The flow rate of the mobile phase $(0.5 \mathrm{mM} 7.4$ phosphate buffer) was maintained at $0.35 \mathrm{~mL} / \mathrm{min}$ for all runs. Full-spectrum UV-visible (200 to $700 \mathrm{~nm}$ ) absorbance spectra were collected for the duration of each run. All quantitative measurements of PolyHb composition were performed from the absorbance at $413 \mathrm{~nm}$. To estimate the $\mathrm{MW}$ distribution of low MW PolyHb, we used the manufacturer provided calibration of the SEC column corrected for the holdup time in the tubing between system components. Autooxidation of ferrous PolyHb $\left(\mathrm{Fe}^{2+}\right)(1.25 \mathrm{~g} / \mathrm{dL})$ to ferric PolyHb $\left(\mathrm{Fe}^{3+}\right)$ was monitored at $37^{\circ} \mathrm{C}$ over 24 hours in a temperature controlled HP 8452 photodiode array spectrophotometer. The resulting spectra were assessed with multicomponent analysis and a two phase linear fit [38] using the segmented fit package in R 3.6.1.

\section{Cell culture and viability}

NSCLC cell lines A549, H23, and H460 were obtained from ATCC (American Type Culture Collection, Manassas, VA, USA). Cells were grown as monolayers and maintained in the exponential growth phase at $5 \%$ 
$\mathrm{CO}_{2}$ in a humidified incubator at $37^{\circ} \mathrm{C}$ under normoxic conditions. Cells were cultured in DMEM (10\% FBS, $100 \mathrm{U} / \mathrm{mL}$ penicillin, $100 \mu \mathrm{g} / \mathrm{mL}$ streptomycin, and $2 \mathrm{mM}$ L-glutamine) (Life Technologies, Carlsbad, CA, USA). Cisplatin [cis-DDP, cis-diamminedichloroplatinum (II), P4394] was purchased from Sigma Aldrich (St Louis, MO, USA). A stock solution of $5 \mathrm{mmol} / \mathrm{L}$ cisplatin was prepared in $0.9 \% \mathrm{NaCl}$ and stored at $-80^{\circ} \mathrm{C}$. Dilutions were made in PBS. Hypoxic conditions $\left(5 \% \mathrm{O}_{2} / 5 \%\right.$ $\mathrm{CO}_{2}$ ) were achieved by connecting a ProOx $\mathrm{O}_{2}$ controller (BioSpherix, Redfield, NY) to the incubator. For in vitro treatments, cells were initially seeded in 96-well plates and after overnight incubation under hypoxic conditions, PolyHb at a final concentration of $0.05 \mathrm{~g} / \mathrm{dL}$ was added in the culture medium and cells were cultured for an additional $24 \mathrm{~h}$. Similarly, for the in vitro cytotoxicity test, cells were pre-seeded into 96 -well plates $\left(1 \times 10^{5}\right.$ per well) and incubated overnight under hypoxic conditions. Then, cells were cultured for an additional $48 \mathrm{~h}$ with and without PolyHb at concentrations of 0.1 and $0.2 \mathrm{~g} / \mathrm{dL}$ in the culture medium, and with different concentrations of cisplatin. A standard methyl thiazolyltetrazolium (MTT, Sigma-Aldrich) assay was used to determine relative cell viability. Six replicates were completed for each of the experimental groups $(n=6)$.

\section{Reactive oxygen species}

Dichlorofluorescindiacetate (DCFH-DA) was used to qualitatively detect the formation of ROS. Non-fluorescent DCFH-DA is oxidized to fluorescent dichlorofluorescein (DCF) by ROS. Cells were plated at 1 $\times 10^{5}$ in a confocal dish and incubated for $24 \mathrm{~h}$. Cells were treated with vehicle $(0.9 \%$ saline $)$ and PolyHb and further incubated with DCFH-DA $(10 \mu \mathrm{M})$ for $15 \mathrm{~min}$ before imaging. Glass dishes were observed by confocal laser scanning microscopy (CLSM). Quantitative analysis of intracellular ROS was conducted after cells were digested and collected by centrifugation (1000 rpm, $5 \mathrm{~min}$ ), and quickly the fluorescence intensity was measured using a Spectra Max M5 spectrofluorometer (Molecular Devices, Sunnyvale, CA, USA) at an excitation of $485 \mathrm{~nm}$ and emission of $535 \mathrm{~nm}$.

\section{Annexin V/propidium iodide staining}

Cells were plated at $5 \times 10^{4}$ cells/well in $24-$ well plates and allowed to attach overnight. PolyHb at concentrations of 0.1 and $0.2 \mathrm{~g} / \mathrm{dL}$ with and without cisplatin at $0.2 \mu \mathrm{M}$ were added to the culture medium. After 48 hours, cells were harvested by trypsinization, centrifuged, and resuspended in $50 \mu \mathrm{L}$ of Annexin $\mathrm{V}$ in binding buffer (10 mmol/L N -2-hydroxyethylpiperazine-N -2-ethanesulfonic acid, $\mathrm{pH} 7.4 ; 150 \mathrm{mmol} / \mathrm{L}$ sodium chloride, $5 \mathrm{mmol} / \mathrm{L}$ potassium chloride; $1 \mathrm{mmol} / \mathrm{L}$ magnesium chloride; and $1.8 \mathrm{mmol} / \mathrm{L}$ calcium chloride).
After 10 minutes of incubation at $4^{\circ} \mathrm{C}, 150 \mu \mathrm{L}$ of annexin $\mathrm{V}$ binding buffer and $20 \mu \mathrm{L}$ of propidium iodide $(100 \mu \mathrm{g} /$ $\mathrm{mL}$ in PBS) were added, and flow cytometry (FACScan; BD Immunocytometry Systems, San Jose, Calif) was performed. For every experiment, a minimum of $1 \times 10^{4}$ cells was analyzed, and single- and double-labeled cells were counted, and the percentages of cells labeled with annexin $\mathrm{V}$ and/or propidium iodide were calculated. All experiments were performed with 6 replicates $(n=6)$.

\section{Western blot analysis}

Cells were treated with either vehicle $(0.9 \%$ saline) or PolyHb for $24 \mathrm{~h}$ under hypoxic conditions. Total cell extracts were prepared by incubating cells at $4^{\circ} \mathrm{C}$ for $30 \mathrm{~min}$ in lysis buffer and a mixture of protease inhibitors (Sigma-Adrich). Proteins were transferred to polyvinylidene difluoride (Merck Millipore, Burlington, MA) or nitrocellulose (Biorad) membranes. The following antibodies were used: P53 (Cell Signalling Technology, Danvers, MA, no. 9282; 1:1000); and HIF-1 $\alpha$ (Abcam, 1:1000, ab82832), HIF-2 $\alpha$ (Santa Cruz, sc-28706); and Actin (Sigma-Aldrich). Image J software was used to quantify the relative density of the Western blot bands and was presented as an adjusted relative density (area sample/ area standard/area loading control sample/area loading control standard).

\section{Animal preparation}

All protocols were approved by the Institutional Animal Care and Use Committee of the University of California, San Diego, and conducted according to the Guide for the Care and Use of Laboratory Animals (US National Research Council, 2011). All cells were tested for mycoplasma prior to inoculation in mice. Female BALB/c nude mice $(22 \pm 3 \mathrm{~g})$ were subcutaneously injected with $5 \times 10^{6}$ of A549 cells suspended in PBS and containing 50\% Matrigel Matrix (Coining, 354234). Female athymic nude (Foxn $\left.1^{\mathrm{nu}}\right)$ mice $(20 \pm 2 \mathrm{~g})$ were subcutaneously injected with $1 \times 10^{7} \mathrm{H} 23$ cells or $5 \times 10^{6} \mathrm{H} 460$ cells into the right hind flank suspended in PBS and Matrigel Matrix (Coining, 354234) to establish additional NSCLC xenograft models. Mice began receiving treatment once tumors reached approximately $200 \mathrm{~mm}^{3}$ ( $\left.\pm 15 \%\right)$. Tumor volume was calculated as length $\times$ width $\times$ width $/ 2$. Cisplatin was administered intraperitoneally twice a week $(\mathrm{q} 7 \mathrm{~d} \times 2$, IP) at $3 \mathrm{mg} / \mathrm{kg}$ (at $8 \mathrm{~mL} / \mathrm{kg}$ ) and PolyHb was administered IV through the tail vein once a week.

\section{Statistical analysis}

Values are presented as means and standard deviations (SD). The data were analyzed and plotted using Graphpad. Student's $t$-test (two-tailed) or one-way ANOVA was performed to determine significance when 
comparing data from different treatment groups. $P$ values were calculated, and $P<0.05$ was considered to represent a significant difference.

\section{CONCLUSIONS}

This study confirms that HBOCs combined with an anticancer drug can enhance the sensitivity of the tumor to chemotherapy, suggesting a new approach for treating patients suffering from NSCLC tumors. Therefore, infusing PolyHb as a co therapeutic may lead to reduced chemotherapeutic doses, which can reduce chemotherapeutic toxicity while improving the efficacy of the current standard-of-care. Hence, we believe that PolyHb combined with an anticancer drug is a promising approach towards tumor oxygenation and ROS formation, therefore increasing the sensitivity of chemotherapy in tumor treatment. The resulting improvement in therapeutic outcomes will be useful and practical in clinical situations.

\section{Author contributions}

$\mathrm{AL}$ and $\mathrm{DAB}$ wrote the main manuscript text. AL and $\mathrm{DAB}$ performed the experiments. AL, DAB, CM, and ATW analyzed the data. AL and DAB prepared the figures. AFP and PC conceived the rationale and strategy for the study, and contributed to the design of experiments. All authors reviewed and revised the manuscript, and all authors approved the manuscript text.

\section{ACKNOWLEDGMENTS}

This work was supported by the following: National Institute of Health grants R56HL123015, R01HL126945, R01HL138116, and R01EB021926; National Cancer Institute Grant R01CA188652; and the Pelotonia Graduate Research Fellowship.

\section{CONFLICTS OF INTEREST}

Authors have no conflicts of interest to declare.

\section{REFERENCES}

1. American Cancer Society. Facts \& Figures 2019. American Cancer Society; 2019.

2. Zappa C, Mousa SA. Non-small cell lung cancer: current treatment and future advances. Transl Lung Cancer Res. 2016; 5:288-300. https://doi.org/10.21037/tlcr.2016.06.07. [PubMed]

3. Bareschino MA, Schettino C, Rossi A, Maione P, Sacco PC, Zeppa R, Gridelli C. Treatment of advanced non small cell lung cancer. J Thorac Dis. 2011; 3:122-133. https://doi. org/10.3978/j.issn.2072-1439.2010.12.08. [PubMed]
4. Kelly K, Crowley J, Bunn PA, Presant CA, Grevstad PK, Moinpour CM, Ramsey SD, Wozniak AJ, Weiss GR, Moore DF, Israel VK, Livingston RB, Gandara DR. Randomized Phase III Trial of Paclitaxel Plus Carboplatin Versus Vinorelbine Plus Cisplatin in the Treatment of Patients With Advanced Non-Small-Cell Lung Cancer: A Southwest Oncology Group Trial. J Clin Oncol. 2001; 19:3210-3218. https://doi.org/10.1200/JCO.2001.19.13.3210. [PubMed]

5. Schiller JH, Harrington D, Belani CP, Langer C, Sandler A, Krook J, Zhu J, Johnson DH. Comparison of Four Chemotherapy Regimens for Advanced Non-Small-Cell Lung Cancer. N Engl J Med. 2002; 346:92-98. https://doi. org/10.1056/NEJMoa011954. [PubMed]

6. Guo Q, Lan F, Yan X, Xiao Z, Wu Y, Zhang Q. Hypoxia exposure induced cisplatin resistance partially via activating p53 and hypoxia inducible factor- $1 \alpha$ in non-small cell lung cancer A549 cells. Oncol Lett. 2018; 16:801-808. https:// doi.org/10.3892/ol.2018.8767. [PubMed]

7. Deben C, Deschoolmeester V, De Waele J, Jacobs J, Van den Bossche J, Wouters A, Peeters M, Rolfo C, Smits E, Lardon F, Pauwels P. Hypoxia-Induced Cisplatin Resistance in Non-Small Cell Lung Cancer Cells Is Mediated by HIF$1 \alpha$ and Mutant p53 and Can Be Overcome by Induction of Oxidative Stress. Cancers (Basel). 2018; 10:126. https://doi. org/10.3390/cancers 10040126. [PubMed]

8. Wu HM, Jiang ZF, Ding PS, Shao LJ, Liu RY. Hypoxiainduced autophagy mediates cisplatin resistance in lung cancer cells. Sci Rep. 2015; 5:12291. https://doi. org/10.1038/srep12291. [PubMed]

9. Gong T, Cui L, Wang H, Wang H, Han N. Knockdown of KLF5 suppresses hypoxia-induced resistance to cisplatin in NSCLC cells by regulating HIF-1 $\alpha$-dependent glycolysis through inactivation of the PI3K/Akt/mTOR pathway. J Transl Med. 2018; 16:164. https://doi.org/10.1186/s12967018-1543-2. [PubMed]

10. Masoud GN, Li W. HIF-1 $\alpha$ pathway: role, regulation and intervention for cancer therapy. Acta Pharm Sin B. 2015; 5:378389. https://doi.org/10.1016/j.apsb.2015.05.007. [PubMed]

11. Chandel NS, McClintock DS, Feliciano CE, Wood TM, Melendez JA, Rodriguez AM, Schumacker PT. Reactive Oxygen Species Generated at Mitochondrial Complex III Stabilize Hypoxia-inducible Factor- $1 \alpha$ during Hypoxia A Mechanism Of O2 Sensing. J Biol Chem. 2000; 275:2513025138. https://doi.org/10.1074/jbc.M001914200. [PubMed]

12. Chandel NS, Maltepe E, Goldwasser E, Mathieu CE, Simon MC, Schumacker PT. Mitochondrial reactive oxygen species trigger hypoxia-induced transcription. Proc Natl Acad Sci U S A. 1998; 95:11715-11720. https://doi. org/10.1073/pnas.95.20.11715. [PubMed]

13. Zhao T, Zhu Y, Morinibu A, Kobayashi M, Shinomiya K, Itasaka S, Yoshimura M, Guo G, Hiraoka M, Harada H. HIF-1-mediated metabolic reprogramming reduces ROS levels and facilitates the metastatic colonization of cancers in lungs. Sci Rep. 2014; 4:3793. https://doi.org/10.1038/ srep03793. [PubMed] 
14. Dasari S, Tchounwou PB. Cisplatin in cancer therapy: molecular mechanisms of action. Eur J Pharmacol. 2014; 740:364-78. https://doi.org/10.1016/j.ejphar.2014.07.025. [PubMed]

15. Dzamitika S, Salerno M, Pereira-Maia E, Le Moyec L, Garnier-Suillerot A. Preferential energy- and potentialdependent accumulation of cisplatin-gutathione complexes in human cancer cell lines (GLC4 and K562): A likely role of mitochondria. J Bioenerg Biomembr. 2006; 38:11-21. https://doi.org/10.1007/s10863-006-9001-x. [PubMed]

16. Godbout JP, Pesavento J, Hartman ME, Manson SR, Freund GG. Methylglyoxal enhances cisplatin-induced cytotoxicity by activating protein kinase Cdelta. J Biol Chem. 2002; 277:2554-2561. https://doi.org/10.1074/jbc.M100385200. [PubMed]

17. Rybak LP, Whitworth C, Somani S. Application of antioxidants and other agents to prevent cisplatin ototoxicity. Laryngoscope. 1999; 109:1740-1744. https:// doi.org/10.1097/00005537-199911000-00003. [PubMed]

18. Itoh T, Terazawa R, Kojima K, Nakane K, Deguchi T, Ando M, Tsukamasa Y, Ito M, Nozawa Y. Cisplatin induces production of reactive oxygen species via NADPH oxidase activation in human prostate cancer cells. Free Radic Res. 2011; 45:1033-1039. https://doi.org/10.3109/10715762.20 11.591391. [PubMed]

19. Choi YM, Kim HK, Shim W, Anwar MA, Kwon JW, Kwon HK, Kim HJ, Jeong H, Kim HM, Hwang D, Kim HS, Choi S. Mechanism of Cisplatin-Induced Cytotoxicity Is Correlated to Impaired Metabolism Due to Mitochondrial ROS Generation. PLoS One. 2015; 10:e0135083. https:// doi.org/10.1371/journal.pone.0135083. [PubMed]

20. Lee NP, Chan KT, Choi MY, Lam HY, Tung LN, Tzang FC, Han H, Lam IPY, Kwok SY, Lau SH, Man C, Tong DK, Wong BL, et al. Oxygen carrier YQ23 can enhance the chemotherapeutic drug responses of chemoresistant esophageal tumor xenografts. Cancer Chemother Pharmacol. 2015; 76:1199-1207. https://doi.org/10.1007/ s00280-015-2897-2. [PubMed]

21. Li CX, Wong BL, Ling CC, Ma YY, Shao Y, Geng W, Qi X, Lau SH, Kwok SY, Wei N, Tzang FC, Ng KT, Liu XB, et al. A novel oxygen carrier 'YQ23' suppresses the liver tumor metastasis by decreasing circulating endothelial progenitor cells and regulatory T cells. BMC Cancer. 2014; 14:293. https://doi.org/10.1186/1471-2407-14-293. [PubMed]

22. Qi X, Wong BL, Lau SH, Ng KT, Kwok SY, Kin-Wai Sun C, Tzang FC, Shao Y, Li CX, Geng W, Ling CC, Ma YY, Liu XB, et al. A hemoglobin-based oxygen carrier sensitized Cisplatin based chemotherapy in hepatocellular carcinoma. Oncotarget. 2017; 49; 85311-85325. https://doi. org/10.18632/oncotarget.19672. [PubMed]

23. Han J, Yu M, Dai M, Cui P, Li H, Zhang J, Liu Q, Xiu R. Effect of Artificial Oxygen Carrier with Chemotherapy on Tumor Hypoxia and Neovascularization. Artif Cells Blood Substit Immobil Biotechnol. 2008; 36:431-438. https://doi. org/10.1080/10731190802369789. [PubMed]
24. Wu W, Yang Q, Wu W, Yang Q, Li T, Zhang P, Zhou R, Yang C. Hemoglobin-based Oxygen Carriers Combined with Anticancer Drugs May Enhance Sensitivity of Radiotherapy and Chemotherapy to Solid Tumors. Artif Cells Blood Substit Immobil Biotechnol. 2009; 37:163-165. https://doi.org/10.1080/10731190903043218. [PubMed]

25. Murayama C, Kawaguchi AT, Ishikawa K, Kamijo A, Kato N, Ohizumi Y, Sadahiro S, Haida M. LiposomeEncapsulated Hemoglobin Ameliorates Tumor Hypoxia and Enhances Radiation Therapy to Suppress Tumor Growth in Mice. Artif Organs. 2012; 36:170-177. https:// doi.org/10.1111/j.1525-1594.2011.01418.x. [PubMed]

26. Belcher DA, Ju JA, Baek JH, Yalamanoglu A, Buehler PW, Gilkes DM, Palmer AF. The quaternary state of polymerized human hemoglobin regulates oxygenation of breast cancer solid tumors: A theoretical and experimental study. PLoS One. 2018; 13:e0191275. https://doi.org/10.1371/journal. pone.0191275. [PubMed]

27. Xu H, Bjerneld EJ, Käll M, Börjesson L. Spectroscopy of Single Hemoglobin Molecules by Surface Enhanced Raman Scattering. Phys Rev Lett. 1999; 83:4357-4360. https://doi. org/10.1103/PhysRevLett.83.4357.

28. Teicher BA, Holden SA, Menon K, Hopkins RE, Gawryl MS. Effect of hemoglobin solution on the response of intracranial and subcutaneous 9L tumors to antitumor alkylating agents. Cancer Chemother Pharmacol. 1993; 33:57-62. https://doi.org/10.1007/BF00686024. [PubMed]

29. Teicher BA, Herman TS, Hopkins RE, Menon K. Effect of a bovine hemoglobin preparation on the response of the FSaIIC fibrosarcoma to chemotherapeutic alkylating agents. J Cancer Res Clin Oncol. 1992; 118:123-128. https://doi. org/10.1007/BF01187500. [PubMed]

30. Yamamoto M, Izumi Y, Horinouchi H, Teramura Y, Sakai H, Kohno M, Watanabe M, Kawamura M, Adachi T, Ikeda E, Takeoka S, Tsuchida E, Kobayashi K. Systemic administration of hemoglobin vesicle elevates tumor tissue oxygen tension and modifies tumor response to irradiation. J Surg Res. 2009; 151:48-54. https://doi.org/10.1016/j. jss.2007.12.770. [PubMed]

31. Belcher DA, Banerjee U, Baehr CM, Richardson KE, Cabrales P, Berthiaume F, Palmer AF. Mixtures of tense and relaxed state polymerized human hemoglobin regulate oxygen affinity and tissue construct oxygenation. PLoS One. 2017; 12:e0185988. https://doi.org/10.1371/journal. pone.0185988. [PubMed]

32. Rifkind JM, Mohanty JG, Nagababu E. The pathophysiology of extracellular hemoglobin associated with enhanced oxidative reactions. Front Physiol. 2015; 5:500. https://doi.org/10.3389/fphys.2014.00500. [PubMed]

33. Rifkind JM, Nagababu E, Ramasamy S, Ravi LB. Hemoglobin redox reactions and oxidative stress. Redox Rep. 2003; 8:234-237. https://doi. org/10.1179/135100003225002817. [PubMed]

34. Kassa T, Jana S, Meng F, Alayash A. Differential heme release from various hemoglobin redox states and the 
upregulation of cellular heme oxygenase-1. FEBS Open Bio. 2016; 6:876-884. https://doi.org/10.1002/22115463.12103. [PubMed]

35. Yeh LH, Alayash AI. Redox side reactions of haemoglobin and cell signalling mechanisms1. J Intern Med.

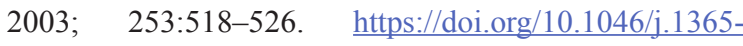
2796.2003.01152.x. [PubMed]

36. Yang Q, Wu W, Li Q, Chen C, Zhou R, Qiu Y, Luo M, Tan Z, Li S, Chen G, Zhou W, Liu J, Yang C, et al. HighDose Polymerized Hemoglobin Fails to Alleviate Cardiac Ischemia/Reperfusion Injury due to Induction of Oxidative Damage in Coronary Artery. Oxid Med Cell Longev. 2015; 2015:125106. https://doi.org/10.1155/2015/125106. [PubMed]

37. Wu M, Feng K, Li Q, Ma H, Zhu H, Xie Y, Yan G, Chen C, Yan K. Glutaraldehyde-polymerized hemoglobin and tempol (PolyHb-tempol) has superoxide dismutase activity that can attenuate oxidative stress on endothelial cells induced by superoxide anion. Artif Cells Nanomed Biotechnol. 2018; 46:47-55. https://doi.org/10.1080/2169 1401.2017.1328685. [PubMed]

38. Belcher DA, Cuddington CT, Martindale EL, Pires IS, Palmer AF. Controlled Polymerization and Ultrafiltration Increase the Consistency of Polymerized Hemoglobin for Use as an Oxygen Carrier. Bioconjug Chem. 2020; 31:605621. https://doi.org/10.1021/acs.bioconjchem.9b00766. [PubMed]

39. Meng F, Kassa T, Jana S, Wood F, Zhang X, Jia Y, D'Agnillo F, Alayash AI. Comprehensive Biochemical and Biophysical Characterization of Hemoglobin-Based Oxygen Carrier Therapeutics: All HBOCs Are Not Created Equally. Bioconjug Chem. 2018; 29:1560-1575. https://doi. org/10.1021/acs.bioconjchem.8b00093. [PubMed]

40. Aruoma OI, Halliwell B, Hoey BM, Butler J. The antioxidant action of $\mathrm{N}$-acetylcysteine: Its reaction with hydrogen peroxide, hydroxyl radical, superoxide, and hypochlorous acid. Free Radic Biol Med. 1989; 6:593-597. https://doi.org/10.1016/0891-5849(89)90066-X. [ubMed]

41. Kuang Y, Wang Q. Iron and lung cancer. Cancer Lett. 2019; 464:56-61. https://doi.org/10.1016/j.canlet.2019.08.007. [PubMed]

42. Matsumoto M, Nakajima W, Seike M, Gemma A, Tanaka N. Cisplatin-induced apoptosis in non-small-cell lung cancer cells is dependent on Bax- and Bak-induction pathway and synergistically activated by BH3-mimetic ABT-263 in p53 wild-type and mutant cells. Biochem Biophys Res Commun. 2016; 473:490-496. https://doi.org/10.1016/j. bbrc.2016.03.053. [PubMed]

43. Wallace WJ, Maxwell JC, Caughey WS. A role for chloride in the autoxidation of hemoglobin under conditions similar to those in erythrocytes. FEBS Lett. 1974; 43:33-36. https:// doi.org/10.1016/0014-5793(74)81099-9. [PubMed]

44. Tsuruga M, Matsuoka A, Hachimori A, Sugawara Y, Shikama K. The Molecular Mechanism of Autoxidation for Human Oxyhemoglobin tilting of the distal histidine causes nonequivalent oxidation in the $\beta$ chain. J Biol Chem. 1998; 273:8607-8615. https://doi.org/10.1074/jbc.273.15.8607. [PubMed]

45. Kato Y, Ozawa S, Miyamoto C, Maehata Y, Suzuki A, Maeda T, Baba Y. Acidic extracellular microenvironment and cancer. Cancer Cell Int. 2013; 13:89. https://doi. org/10.1186/1475-2867-13-89. [PubMed]

46. Navati MS, Lucas A, Liong C, Barros M, Jayadeva JT, Friedman JM, Cabrales P. Reducing Ischemia/Reperfusion Injury by the Targeted Delivery of Nitric Oxide from Magnetic-Field-Induced Localization of S-NitrosothiolCoated Paramagnetic Nanoparticles. ACS Appl Bio Mater. 2019. https://doi.org/10.1021/acsabm.9b00282.

47. Lucas A. Use of Hyperspectral Imaging for the Study of Hemoglobin Oxygen Saturation in the Microcirculation. UC San Diego; 2019.

48. Palmer AF, Sun G, Harris DR. Tangential flow filtration of hemoglobin. Biotechnol Prog. 2009; 25:189-199. https:// doi.org/10.1002/btpr.119. [PubMed]

49. Arifin DR, Palmer AF. Determination of Size Distribution and Encapsulation Efficiency of Liposome-Encapsulated Hemoglobin Blood Substitutes Using Asymmetric Flow Field-Flow Fractionation Coupled with Multi-Angle Static Light Scattering. Biotechnol Prog. 2003; 19:1798-1811. https://doi.org/10.1021/bp034120x. [PubMed]

50. Hawk PB. Blood analysis. In: Hawk's Physiological Chemistry. New York: McGraw-Hill. 1965; 14:1090-1099. 